\title{
Circulating concentrations of B group vitamins and urothelial cell carcinoma
}

Authors: Julie K Bassett ${ }^{1}$, Maree T Brinkman ${ }^{1}$, Pierre-Antoine Dugué ${ }^{1,2}$, Per M Ueland ${ }^{3,4}$, Øivind Midttun $^{5}$, Arve Ulvik ${ }^{5}$, Damien Bolton ${ }^{6}$, Melissa C Southey ${ }^{7,8}$, Dallas R English ${ }^{1,2}$, Roger L Milne ${ }^{1,2}$, Allison M Hodge ${ }^{1,2}$, Graham G Giles ${ }^{1,2}$

\section{Author affiliations:}

${ }^{1}$ Cancer Epidemiology and Intelligence Division, Cancer Council Victoria, Melbourne, VIC 3004, Australia

${ }^{2}$ Centre for Epidemiology and Biostatistics, Melbourne School of Population and Global Health, University of Melbourne, Parkville, VIC 3052, Australia

${ }^{3}$ Department of Clinical Science, University of Bergen, Bergen, Norway

${ }^{4}$ Laboratory of Clinical Biochemistry, Haukeland University Hospital, Bergen, Norway

${ }^{5}$ Bevital AS, Bergen, Norway

${ }^{6}$ Department of Surgery, Austin Health, University of Melbourne, VIC 3084, Australia

${ }^{7}$ Genetic Epidemiology Laboratory, Department of Pathology, University of Melbourne, Melbourne, VIC 3000, Australia

${ }^{8}$ Precision Medicine, School of Clinical Sciences, Monash University, Clayton, VIC 3168, Australia

\section{Corresponding author:}

Julie K Bassett

Cancer Epidemiology and Intelligence Division

Cancer Council Victoria

615 St Kilda Road

Melbourne, Victoria 3004

Australia

Phone: +6139514 6244

Fax: $\quad+61395146800$

Email: Julie.Bassett@cancervic.org.au

Short title: Plasma B vitamins and urothelial cell carcinoma

Keywords: B vitamins; urothelial cell carcinoma; bladder cancer; Melbourne Collaborative Cohort Study
Abbreviations:
BMI
body mass index
CI
confidence interval
CIS
Carcinoma in Situ
DAG directed acyclic graph
EPIC
European Prospective Investigation into Cancer and Nutrition

This is the author manuscript accepted for publication and has undergone full peer review but has not been through the copyediting, typesetting, pagination and proofreading process, which may lead to differences between this version and the Version of Record. Please cite this article as doi: $10.1002 / \mathrm{ijc} .31927$ 


$\begin{array}{ll}\text { FFQ } & \text { food frequency questionaire } \\ \text { FMN } & \text { flavin mononucleotide } \\ \text { HR } & \text { hazard ratio } \\ \text { ICD } & \text { International Classification of Diseases } \\ \text { MCCS } & \text { Melbourne Collaborative Cohort Study } \\ \text { MDS } & \text { Mediterranean diet score } \\ \text { OR } & \text { odds ratio } \\ \text { Q } & \text { quartile } \\ \text { UCC } & \text { urothelial cell carcinoma } \\ \text { VCR } & \text { Victorian Cancer Registry } \\ \text { WCRF } & \text { World Cancer Research Fund }\end{array}$

\section{Article category: Cancer epidemiology}

Conflict of interest: The authors have no conflict of interest to declare.

\section{Novelty and Impact:}

$\mathrm{B}$ vitamins are involved in one-carbon metabolism and hypothesised to influence carcinogenesis. Studies investigating B vitamin intakes and urothelial cell carcinoma have been inconsistent, possibly due to measurement error. This is one of the first prospective studies to look at circulating B vitamins in a large sample. We found no evidence that prediagnostic concentrations of B vitamins were associated with urothelial cell carcinoma risk, or survival for those who had developed this cancer. 


\begin{abstract}
B-group vitamins, as components of the one carbon metabolism pathway, are involved in DNA synthesis, repair and methylation. Our aim was to investigate associations between circulating plasma levels of B vitamins and urothelial cell carcinoma (UCC).

We conducted a nested case-control study of UCC within the Melbourne Collaborative Cohort Study. B vitamins were measured in pre-diagnostic plasma samples. Conditional logistic regression was used to estimate odds ratios (OR) for UCC risk associated with circulating B vitamins in 363 matched cases and controls. In a case-only analysis ( $\mathrm{N}=390)$, hazard ratios (HR) for overall survival associated with plasma B vitamins were estimated using Cox regression.
\end{abstract}

There were no strong associations between UCC risk and pre-diagnostic levels of plasma B vitamins. No heterogeneity in UCC risk was observed by subtype (invasive or superficial), sex, smoking status or alcohol intake. There was no heterogeneity by country of birth for most B vitamins, except for folate (P-homogeneity=0.03). In UCC cases, there were no strong associations between plasma B vitamins and overall survival.

We found no associations between pre-diagnostic plasma concentrations of B-group vitamins and UCC risk or survival.

This article is protected by copyright. All rights reserved. 


\section{Introduction}

Urothelial cell carcinoma (UCC), of which about $90 \%$ originates in the bladder, is one of the most common urological cancers, and is the fourth most commonly diagnosed cancer in males in developed countries ${ }^{1,2}$. More than half of all cases are superficial but recurrence is common, constituting a substantial healthcare burden ${ }^{3}$. Bladder cancer survival is low, especially for women, for whom the 5-year relative survival in 2009-2013 in Australia was 46\%, compared with 55\% for men ${ }^{4}$. Apart from age and sex, the most consistent risk factors are cigarette smoking and occupational exposure to carcinogens such as aromatic amines and polycyclic hydrocarbons which are excreted in the urine ${ }^{2,5}$. Similarly, dietary factors could be involved in the aetiology of UCC given that the urothelium is also exposed to diet-related carcinogens during excretion.

B-group vitamins such as B2, B6, B9 and B12 are involved in the one-carbon metabolism pathway and play a major role in DNA synthesis, repair and methylation ${ }^{6}$. The association between B vitamin intakes and risk of cancers other than UCC has been reported previously from the Melbourne Collaborative Cohort Study (MCCS) ${ }^{7-10}$ but the literature related to UCC risk is limited. The World Cancer Research Fund (WCRF) second expert report concluded that there was only limited evidence to suggest that milk (which is high in vitamin B2) protects against bladder cancer ${ }^{11}$ but the WCRF Continuous Update Project on diet and bladder cancer based on fewer but more recent studies reported that the evidence was too limited to confirm an association ${ }^{12}$. Both reports concluded there was insufficient evidence 
for an association between folate and bladder cancer. Of the few studies that have examined associations between B-vitamins and UCC risk, the majority used dietary data collected with food frequency questionnaires (FFQs) ${ }^{13-16}$. A Spanish case-control study reported inverse associations between B2, B6, B9 and B12 intakes and bladder cancer ${ }^{14}$. A recent metaanalysis reported an inverse association between dietary folate and bladder cancer but this finding was restricted to case-control studies and not present in cohort studies ${ }^{15}$, consistent with the null association we found in a recent MCCS analysis of FFQ-derived dietary intakes of B vitamins ${ }^{17}$. Dietary measures have limitations for assessing the association between these nutrients and UCC. Plasma measures of B-group vitamins may provide a better exposure assessment than reported dietary intakes as the bioavailability of B-group vitamins may be compromised by some drugs, smoking and alcohol intake ${ }^{18}$, gut flora and absorption characteristics (e.g. chronic gastritis ${ }^{19}$ ), liver function or individual genetic factors ${ }^{20,21}$. However, we identified only one study that investigated the association of blood measures of B-group vitamins with UCC ${ }^{22}$. This hospital-based case-control study only investigated folate and reported an inverse association between circulating levels of folate and UCC risk.

While most of the evidence has focussed on occurrence of cancer, higher vitamin B6 concentration has been reported to be inversely associated with survival from prostate cancer and renal cell carcinoma ${ }^{23,24}$. This suggests that circulating levels of B-group vitamins may be informative for both the risk of and survival from UCC. 
The primary aim of this study was to use the MCCS to investigate prospectively the association between pre-diagnostic concentrations of circulating B-group vitamins and UCC risk, and for those who develop UCC, the association between pre-diagnostic plasma B vitamins and survival. Secondary aims were to examine whether associations with risk varied by disease subtype, and in participant subgroups whose nutritional status may be compromised according to smoking status, alcohol consumption and country of birth.

\section{Material and Methods}

Study population

The MCCS is a prospective cohort study of 41514 women and men aged 27 to 75 years (99\% were between 40-69 years) when recruited between 1990 and $1994{ }^{25}$. Italian and Greek migrants were over-sampled to extend the range of lifestyle exposures. Participants were recruited via the electoral rolls (registration to vote is compulsory for adults in Australia), advertisements, and community announcements in local media (e.g. television, radio, and newspapers). Comprehensive lists of Italian and Greek surnames in the phone book and Electoral Rolls were also used to target southern European migrants. The Cancer Council Victoria’s Human Research Ethics Committee approved the study protocol. Participants gave written consent to participate and for the investigators to obtain access to their medical records. Vital status and cause of death information were obtained via linkage to the National Death Index of Australia.

The nested case-control study 
We conducted a case-control study nested within the MCCS (supplementary Figure 1). Participants were excluded if they had a diagnosis of UCC or a cancer with an unknown primary site when the blood sample was collected, or if they had missing data for any of the matching variables. Incident cases were identified from first diagnoses of UCC (morphology codes 8120, 8122, 8130 and 8131 of the International Classification of Diseases, ICD-0-3) to the Victorian Cancer Registry (VCR) or the Australian Cancer Database (for cases diagnosed outside Victoria) to 31 December 2012. Controls were selected by incidence density sampling using age as the time axis and matched to cases on year of birth, country of birth, sex, type of blood sample (buffy coat, Guthrie card or lymphocyte) and sample collection period (baseline (study entry) or follow-up). Although, all blood samples used for measurements of B vitamins were collected at study entry (1990-94) before UCC diagnosis, this nested case-control sample was originally set up to investigate associations between DNA methylation and UCC risk, which required matching on blood sample type ${ }^{26}$.

Participants with a primary diagnosis of UCC (excluding ICD-0-3 C529 and those classified with uncertain behaviour) were included as cases. Disease subtypes were defined according to behaviour, with invasive UCC including any tumour that had penetrated or invaded the basement membrane (pT1-4). Superficial UCC included papillary transitional/ urothelial cell neoplasm of low malignant potential or Carcinoma in Situ (CIS) that was completely confined within the epithelium (pTa-pTcis). 
We excluded participants with missing data for any of the confounders $(\mathrm{N}=14)$. For the conditional logistic regression analyses we excluded any cases or controls without a matched pair.

\section{Biochemical analyses}

Following blood draw, plasma fractions were stored in liquid nitrogen tanks at $-196^{\circ} \mathrm{C}$ until shipment to the laboratory for analysis. Plasma samples were sent on dry ice to the Bevital A/S laboratory (http://www.bevital.no) in Bergen, Norway for measurements of plasma concentrations of vitamin B2 (riboflavin plus flavin mononucleotide (FMN)), vitamin B3 (nicotinamide), vitamin B6 (pyridoxal 5'-phosphate, its active form), vitamin B9 (folate, predominantly 5-methyltetrahydrofolate) and vitamin B12 (cobalamin). Cotinine was also measured as an indicator of recent smoking behaviour. Concentrations of vitamin B2, B3, B6, and cotinine were determined by mass spectrometry-based methods (liquid chromatography coupled to tandem mass spectrometry) ${ }^{27}$ and microbiological methods were used to determine concentrations of B9 (Lactobacillus casei) ${ }^{28}$ and B12 (Lactobacillus leich mannii). ${ }^{29}$

\section{Assessment of other risk factors}

A structured interview schedule was used to obtain information on potential risk factors including age, sex, country of birth, alcohol consumption, and smoking status. Height and weight were measured, and body mass index was calculated from these (BMI= weight (kg)/height $(\mathrm{m})^{2}$ ). Participants completed a food frequency questionnaire that was developed 
from a study of weighed food records in 810 Melburnians of similar demographics to the cohort $^{30}$. Nutrient intakes were calculated using mean sex-specific portion sizes from the weighed food records ${ }^{30}$. The Mediterranean Diet Score (MDS) was calculated using intakes of vegetables, fruit, cereals, legumes, fish, dairy, red meat, olive oil and alcohol ${ }^{31}$ and used as a measure of diet quality.

\section{Statistical analysis}

Quartile (Q) cut-points for each circulating B vitamin were calculated from the distribution in controls and applied to the whole sample. Conditional logistic regression models were used to estimate odds ratios (ORs) and 95\% confidence intervals (CIs) for the association between UCC risk and plasma B vitamin concentrations relative to the lowest quartile. Log-linear trends were estimated using the base 2 logarithm ( $\left.\log _{2}\right)$ of each B vitamin as a continuous variable; the estimates from these models can be interpreted as ORs for a doubling in the B vitamin concentration.

Potential confounders were identified from a Directed Acyclic Graph (DAG) ${ }^{32}$ based on existing literature regarding risk factors for UCC. All models were adjusted for smoking status (never, current, former), cotinine level $(0 \mathrm{nmol} / \mathrm{L} ;>0$ to $\leq 85 \mathrm{nmol} / \mathrm{L} ;>85$ to $<1000$ $\mathrm{nmol} / \mathrm{L} ; \geq 1000 \mathrm{nmol} / \mathrm{L}$ ), alcohol intake (none, low intake:1-39g/d (men), 1-19g/d (women); moderate/high intake: $\geq 40 \mathrm{~g} / \mathrm{d}$ (men), $\geq 20 \mathrm{~g} / \mathrm{d}$ (women)), BMI (continuous), country of birth (Australia/New Zealand/United Kingdom/other, Greece and Italy), and MDS (score from 0 to 9). Effect modification was assessed by testing two-way interaction terms (using the 
likelihood ratio test) between each B vitamin and sex, country of birth, smoking status, alcohol intake and time between blood collection and diagnosis ( $\leq 10$ years and $>10$ years). Interactions were fitted between UCC subtype (invasive or superficial) and each B vitamin and results of UCC risk and plasma B vitamins by UCC subtype from these models are also presented. As some of the B vitamin concentrations were correlated, we also performed a principal component analysis of the correlation matrix of the log-transformed (base 2) B vitamins (as they were positively skewed), followed by orthogonal (varimax) rotation of the components obtained from the principal component analysis ${ }^{33,34}$ to identify any distinct combinations of these measures. These components were then included in a conditional logistic regression model to estimate ORs and 95\% CIs for the association between each principal component analysis-defined combination of B vitamins and UCC risk.

For the survival analysis, Cox proportional hazards regression models were fitted to data from UCC cases, using time since diagnosis as the timescale, to estimate hazard ratios (HRs) and 95\% confidence intervals (CIs) for overall survival. Person-time began at date of UCC diagnosis and ended at the earliest of date of death, date left Australia or 31 December 2014 (the date at which death data was complete). Models were adjusted for country of birth, sex, smoking status, cotinine level, alcohol intake, BMI, age at UCC diagnosis and MDS score (0$3 ; 4-6 ; 7-9)$.

To investigate departure from linearity in the relationship between plasma B vitamins and overall UCC risk and survival in UCC cases we included a quadratic term for each plasma B 
vitamin and used the likelihood ratio test to test for a quadratic trend. We performed sensitivity analyses (1) restricted to participants who were not using multi-vitamins at the time of blood collection; too few people were using multivitamins to assess associations in users, and (2) excluding participants with a cancer diagnosis at any site prior to blood collection. Tests based on Schoenfeld residuals showed no evidence of violation of the proportional hazards assumption except for the MDS so we stratified the Cox models on this variable. All statistical tests were two sided. Statistical analyses were performed using Stata/MP 14.2® (Stata Corporation, College Station, TX).

\section{Results}

B vitamins were measured in pre-diagnostic plasma samples for 790 participants (supplementary Figure 1). After excluding 14 participants who had missing data for any of the confounders (alcohol intake, $\mathrm{N}=2$; smoking status, $\mathrm{N}=1$; MDS, $\mathrm{N}=2$ ) or for any of the plasma B vitamins (N=12) there were 390 cases and 386 controls. For the analysis of UCC risk (conditional logistic regression), we further excluded 50 participants (27 cases and 23 controls) without a matched pair, leaving 726 available participants (363 cases and 363 controls). Cases with complete data $(\mathrm{N}=390)$ were used for the analysis of UCC survival.

Participant characteristics at the time of blood collection are given in Table 1. Cases had slightly lower levels of total B2, riboflavin, FMN and B3, and higher B12 and were more likely to be current or former smokers. Pearson correlation coefficients between the base 2 log transformed B vitamin measures are shown in Table 2. Total B2 is the sum of riboflavin 
and FMN, and as expected showed high to moderate correlations with riboflavin $(\mathrm{r}=0.98)$ and FMN ( $\mathrm{r}=0.54)$. Riboflavin and FMN were moderately correlated ( $\mathrm{r}=0.36)$. Moderate correlations were also observed for vitamin B6 and riboflavin $(\mathrm{r}=0.35)$, total $\mathrm{B} 2(\mathrm{r}=0.35)$ and B9 $(r=0.25)$, all other correlations were weak.

Table 3 shows the ORs for UCC risk in relation to plasma B vitamin levels, overall and by UCC subtype. There was no evidence of a quadratic trend for any of the B vitamins ( $\mathrm{P}>0.09)$. There was a weak inverse association between UCC risk and total $\mathrm{B} 2\left(\mathrm{OR}_{\mathrm{Q} 4 \text { vs } \mathrm{Q} 1}=0.66\right.$ $(0.42,1.05)$; $\left.\mathrm{P}_{\text {trend }}=0.11\right)$ with a $16 \%$ reduction in UCC risk for a doubling of plasma $\mathrm{B} 2$. No associations were seen between UCC risk and other B vitamins, nor were there differences by subtype except for vitamin B9 where there was a weak positive association with superficial disease $(\mathrm{P}=0.04)$ but no association for invasive disease $(\mathrm{P}$-homogeneity $=$ 0.06). There were no differences in the ORs for UCC risk and any of the B vitamins by sex, smoking status, alcohol intake, time between blood collection and diagnosis or country of birth, except for vitamin B9 by country of birth (P-homogeneity=0.03); participants of Italian origin had an increased risk of UCC (OR=2.12 (1.21, 3.70) for a doubling of plasma B9) and no association was found for other participants (Table 4).

Following the principal components analysis we used the varimax rotation which derived 3 components characterised by (i) high loadings on B2, B6 and B9 (ii) high loadings on B3 and low loadings on B9 and (iii) high loadings on B12. These components explained $72 \%$ of the total variance, but none were associated with UCC risk (data not shown). 
A total of 390 cases, 173 of whom died, were included in the survival analyses (Table 5).

There was no evidence of a quadratic trend for any of the $\mathrm{B}$ vitamins $(\mathrm{P}>0.16)$. There were no associations between any of the plasma B vitamins and overall survival in the UCC cases.

Consistent results for UCC risk and overall survival were observed after restricting to participants who were not taking multivitamins at time of blood collection ( $\mathrm{N}=292$ matched case-control pairs and N=346 cases for the UCC risk and survival analyses respectively) and after excluding anyone who had been diagnosed with cancer at any site prior to blood collection ( $\mathrm{N}=335$ matched case-control pairs and $\mathrm{N}=373$ cases for the UCC risk and survival analyses respectively).

\section{Discussion}

We did not find strong evidence that the risk of UCC was associated with plasma concentrations of B-group vitamins. Smoking, alcohol, or country of birth did not appear to modify associations with UCC risk. There was also no evidence that B-group vitamins were differently associated with risk of superficial or invasive tumours. No association between plasma B vitamins and overall survival of UCC cases was observed.

Our study had the advantage of assessing plasma concentrations of B-group vitamins prior to diagnosis, avoiding any effects related to UCC such as treatment, physiological changes due to the disease process or behavioural changes due to illness. Another strength of our study 
was the availability of a wide range of potential confounders to take into consideration in the analyses, including cotinine, as an additional control for smoking exposure.

Weaknesses of our study included having only a single blood measure for analysis. However, vitamins B2, B6, B9 and B12 had good within-person reproducibility (ICCs range from 0.61 to 0.87 ) in plasma from healthy women in the Nurses' Health Study collected on two occasions 1-2 years apart ${ }^{35}$. Other biomarkers of B vitamin status such as homocysteine and methylmalonic acid were unavailable.

The European Prospective Investigation into Cancer and Nutrition (EPIC) study reported inverse associations between plasma B6 and the risk of breast ${ }^{36}$, gastric ${ }^{37}$, colorectal $^{38}$ and lung cancer ${ }^{39}$ and a positive association for prostate cancer ${ }^{40}$. Inverse associations between plasma B6 and renal cell carcinoma risk and survival have also been reported by EPIC and the MCCS ${ }^{24}$. We found no evidence for an association of B6 with UCC incidence or survival.

The EPIC study reported a positive association between folate and lung cancer in smokers ${ }^{39}$. A Swedish cohort study reported elevated ORs for all quintiles of plasma concentrations of folate and risk of colorectal cancer (CRC) relative to the lowest quintile, with the middle quintile associated with the highest risk ${ }^{41}$. We did not see any association of folate (B9) with UCC except in the Italian-born subgroup. This positive association we observed is not consistent with our hypotheses and could be due to chance. 
The EPIC study also reported inverse associations between circulating vitamin B2 and risk of breast $^{36}$, gastric ${ }^{37}$ and colorectal ${ }^{38}$ cancers; a positive association with prostate cancer ${ }^{40}$ and no association with renal cell carcinoma ${ }^{24}$ or lung cancer ${ }^{39}$. A recent meta-analysis reported inverse associations between serum vitamin B2 and other nutrients from the one carbon metabolism pathway (B6, B9 and B12) with renal cell cancer risk ${ }^{42}$. We found a weak inverse association between vitamin B2 and UCC risk. Animal studies have shown that vitamin B2 has anti-carcinogenic properties, such as detoxifying pathogens that can potentially affect the integrity of the epithelium at body sites like the lungs and oesophagus, but its role in risk of developing UCC in humans remains unclear ${ }^{43,44}$.

Dietary studies from the MCCS ${ }^{7-10}$ have examined associations between B vitamin intakes and risk for several cancers but have only found inconsistent or weak associations. We also found no association between dietary intakes of B vitamins and UCC in our prospective cohort ${ }^{17}$. These findings are in contrast to a large Spanish case-control study ${ }^{14}$ which reported protective associations with bladder cancer risk for B2, B6, B9 and B12 intakes. Risk of recall bias and reverse causation are a potential limitation of retrospective casecontrol studies ${ }^{45}$. A recent meta-analysis reported an inverse association between folate intake and UCC risk in case-control studies, but not in cohort studies ${ }^{15}$. In addition to the problems of measuring dietary intakes, individuals vary in their ability to absorb B vitamins and their metabolism of these, hence dietary intake may not accurately reflect the bioavailability of B vitamins ${ }^{20}$. 
Our results do not support associations between any of the B-group vitamins we investigated with either UCC risk or survival.

\section{Acknowledgements}

MCCS cohort recruitment was funded by VicHealth and Cancer Council Victoria. The MCCS was further supported by Australian NHMRC grants 209057 and 396414 and by infrastructure provided by Cancer Council Victoria. The measurement of B vitamins in plasma was supported by Australian NHMRC grant 1043616. Cases and their vital status were ascertained through the Victorian Cancer Registry (VCR) and the Australian Institute of Health and Welfare (AIHW), including the National Death Index and the Australian Cancer Database.

This article is protected by copyright. All rights reserved. 


\section{References}

1. Babjuk M, Bohle A, Burger M, Capoun O, Cohen D, Comperat EM, Hernandez V, Kaasinen E, Palou J, Roupret M, van Rhijn BW, Shariat SF, et al. EAU Guidelines on NonMuscle-invasive Urothelial Carcinoma of the Bladder: Update 2016. Eur Urol 2017;71: 44761.

2. Shariat SF, Sfakianos JP, Droller MJ, Karakiewicz PI, Meryn S, Bochner BH. The effect of age and gender on bladder cancer: a critical review of the literature. BJU Int 2010;105: 300-8. 3. Sievert KD, Amend B, Nagele U, Schilling D, Bedke J, Horstmann M, Hennenlotter J, Kruck S, Stenzl A. Economic aspects of bladder cancer: what are the benefits and costs? World J Urol 2009;27: 295-300.

4. The Australian Institute of Health and Welfare. Cancer in Australia 2017 Available at: https://www.aihw.gov.au/getmedia/3da1f3c2-30f0-4475-8aed-1f19f8e16d48/20066-cancer2017.pdf.aspx?inline=true (accessed on November 2017).

5. Burger M, Catto JW, Dalbagni G, Grossman HB, Herr H, Karakiewicz P, Kassouf W, Kiemeney LA, La Vecchia C, Shariat S, Lotan Y. Epidemiology and risk factors of urothelial bladder cancer. Eur Urol 2013;63: 234-41.

6. de Vogel S, Dindore V, van Engeland M, Goldbohm RA, van den Brandt PA, Weijenberg MP. Dietary folate, methionine, riboflavin, and vitamin B-6 and risk of sporadic colorectal cancer. J Nutr 2008;138: 2372-8.

This article is protected by copyright. All rights reserved. 
7. Bassett JK, Baglietto L, Hodge AM, Severi G, Hopper JL, English DR, Giles GG. Dietary intake of B vitamins and methionine and breast cancer risk. Cancer Causes Control 2013;24: 1555-63.

8. Bassett JK, Hodge AM, English DR, Baglietto L, Hopper JL, Giles GG, Severi G. Dietary intake of B vitamins and methionine and risk of lung cancer. Eur J Clin Nutr 2012;66: 182-7. 9. Bassett JK, Severi G, Hodge AM, Baglietto L, Hopper JL, English DR, Giles GG. Dietary intake of B vitamins and methionine and prostate cancer incidence and mortality. Cancer Causes Control 2012;23: 855-63.

10. Bassett JK, Severi G, Hodge AM, Baglietto L, Hopper JL, English DR, Giles GG. Dietary intake of B vitamins and methionine and colorectal cancer risk. Nutr Cancer 2013;65: 65967.

11. World Cancer Research Fund/American Institute for Cancer Research. Food, Nutrition, Physical Activity, and the Prevention of Cancer: a Global Perspective. Washington DC: AICR. Available at:

http://wcrf.org/sites/default/files/SECOND_EXPERT_REPORT_chapter_07.pdf\#page=69 (accessed on 15 September 2017).

12. World Cancer Research Fund International/American Institute for Cancer Research. Continuous Update Project Report: Diet, Nutrition, Physical Activity and Bladder Cancer Available at: http://www.wcrf.org/int/research-we-fund/continuous-update-project-findingsreports/bladder-cancer (accessed on 15 September 2017). 
13. Brinkman MT, Karagas MR, Zens MS, Schned A, Reulen RC, Zeegers MP. Minerals and vitamins and the risk of bladder cancer: results from the New Hampshire Study. Cancer Causes Control 2010;21: 609-19.

14. Garcia-Closas R, Garcia-Closas M, Kogevinas M, Malats N, Silverman D, Serra C, Tardon A, Carrato A, Castano-Vinyals G, Dosemeci M, Moore L, Rothman N, et al. Food, nutrient and heterocyclic amine intake and the risk of bladder cancer. Eur J Cancer 2007;43: 1731-40.

15. He H, Shui B. Folate intake and risk of bladder cancer: a meta-analysis of epidemiological studies. Int J Food Sci Nutr 2014;65: 286-92.

16. Wu JW, Cross AJ, Baris D, Ward MH, Karagas MR, Johnson A, Schwenn M, Cherala S, Colt JS, Cantor KP, Rothman N, Silverman DT, et al. Dietary intake of meat, fruits, vegetables, and selective micronutrients and risk of bladder cancer in the New England region of the United States. Br J Cancer 2012;106: 1891-8.

17. Dugue PA, Brinkman MT, Hodge AM, Bassett JK, Bolton D, Longano A, Hopper JL, Southey MC, English DR, Milne RL, Giles GG. Dietary intake of nutrients involved in onecarbon metabolism and risk of urothelial cell carcinoma: A prospective cohort study. Int $J$ Cancer 2018; 143: 298-306.

18. Bailey LB. Folate status assessment. J Nutr 1990;120 Suppl 11: 1508-11.

19. Mason JB. Biomarkers of nutrient exposure and status in one-carbon (methyl) metabolism. J Nutr 2003;133 Suppl 3: 941S-7S.

20. O'Leary F, Samman S. Vitamin B12 in health and disease. Nutrients 2010;2: 299-316.

21. Ohrvik VE, Witthoft CM. Human folate bioavailability. Nutrients 2011;3: 475-90.

This article is protected by copyright. All rights reserved. 
22. Chung CJ, Pu YS, Su CT, Chen HW, Huang YK, Shiue HS, Hsueh YM. Polymorphisms in one-carbon metabolism pathway genes, urinary arsenic profile, and urothelial carcinoma. Cancer Causes Control 2010;21: 1605-13.

23. Kasperzyk JL, Fall K, Mucci LA, Hakansson N, Wolk A, Johansson JE, Andersson SO, Andren O. One-carbon metabolism-related nutrients and prostate cancer survival. Am J Clin Nutr 2009;90: 561-9.

24. Johansson M, Fanidi A, Muller DC, Bassett JK, Midttun O, Vollset SE, Travis RC, Palli D, Mattiello A, Sieri S, Trichopoulou A, Lagiou P, et al. Circulating biomarkers of onecarbon metabolism in relation to renal cell carcinoma incidence and survival. J Natl Cancer Inst 2014;106. dju327, https://doi.org/10.1093/jnci/dju327

25. Milne RL, Fletcher AS, MacInnis RJ, Hodge AM, Hopkins AH, Bassett JK, Bruinsma FJ, Lynch BM, Dugue PA, Jayasekara H, Brinkman MT, Popowski LV, et al. Cohort Profile: The Melbourne Collaborative Cohort Study (Health 2020). Int J Epidemiol 2017;46: 1757. 26. Dugue PA, Brinkman MT, Milne RL, Wong EM, FitzGerald LM, Bassett JK, Joo JE, Jung CH, Makalic E, Schmidt DF, Park DJ, Chung J, et al. Genome-wide measures of DNA methylation in peripheral blood and the risk of urothelial cell carcinoma: a prospective nested case-control study. Br J Cancer 2016;115: 664-73.

27. Midttun O, Hustad S, Ueland PM. Quantitative profiling of biomarkers related to Bvitamin status, tryptophan metabolism and inflammation in human plasma by liquid chromatography/tandem mass spectrometry. Rapid Commun Mass Spectrom 2009;23: 13719.

This article is protected by copyright. All rights reserved. 
28. Molloy AM, Scott JM. Microbiological assay for serum, plasma, and red cell folate using cryopreserved, microtiter plate method. Methods Enzymol 1997;281: 43-53.

29. Kelleher BP, Broin SD. Microbiological assay for vitamin B12 performed in 96-well microtitre plates. J Clin Pathol 1991;44: 592-5.

30. Ireland P, Jolley D, Giles G, O’Dea K, Powles J, Rutishauser I, Wahlqvist ML, Williams

J. Development of the Melbourne FFQ: a food frequency questionnaire for use in an Australian prospective study involving an ethnically diverse cohort. Asia Pac J Clin Nutr 1994;3: 19-31.

31. Hodge AM, Bassett JK, Shivappa N, Hebert JR, English DR, Giles GG, Severi G. Dietary inflammatory index, Mediterranean diet score, and lung cancer: a prospective study. Cancer Causes Control 2016;27: 907-17.

32. Rothman KJ, Greenland S, Lash TL. Modern Epidemiology, 3rd ed. Philadelphia: Lipincott Williams and Wilkins, 2008.

33. Abdi H, Williams LJ. Principal Components Analysis. WIREs Comp Stat 2010: 433-59. 34. Jolliffe IT. Principal Components Analysis, $2^{\text {nd }}$ ed. New York: Springer, 2002. 35. Midttun O, Townsend MK, Nygard O, Tworoger SS, Brennan P, Johansson M, Ueland PM. Most blood biomarkers related to vitamin status, one-carbon metabolism, and the kynurenine pathway show adequate preanalytical stability and within-person reproducibility to allow assessment of exposure or nutritional status in healthy women and cardiovascular patients. J Nutr 2014;144: 784-90.

36. Agnoli C, Grioni S, Krogh V, Pala V, Allione A, Matullo G, Di Gaetano C, Tagliabue G, Pedraglio S, Garrone G, Cancarini I, Cavalleri A, et al. Plasma Riboflavin and Vitamin B-6, 
but Not Homocysteine, Folate, or Vitamin B-12, Are Inversely Associated with Breast Cancer Risk in the European Prospective Investigation into Cancer and Nutrition-Varese Cohort. J Nutr 2016;146: 1227-34.

37. Eussen SJ, Vollset SE, Hustad S, Midttun O, Meyer K, Fredriksen A, Ueland PM, Jenab M, Slimani N, Ferrari P, Agudo A, Sala N, et al. Vitamins B2 and B6 and genetic polymorphisms related to one-carbon metabolism as risk factors for gastric adenocarcinoma in the European prospective investigation into cancer and nutrition. Cancer Epidemiol Biomarkers Prev 2010;19: 28-38.

38. Eussen SJ, Vollset SE, Hustad S, Midttun O, Meyer K, Fredriksen A, Ueland PM, Jenab M, Slimani N, Boffetta P, Overvad K, Thorlacius-Ussing O, et al. Plasma vitamins B2, B6, and B12, and related genetic variants as predictors of colorectal cancer risk. Cancer Epidemiol Biomarkers Prev 2010;19: 2549-61.

39. Johansson M, Relton C, Ueland PM, Vollset SE, Midttun O, Nygard O, Slimani N, Boffetta P, Jenab M, Clavel-Chapelon F, Boutron-Ruault MC, Fagherazzi G, et al. Serum B vitamin levels and risk of lung cancer. JAMA 2010;303: 2377-85.

40. Johansson M, Van Guelpen B, Vollset SE, Hultdin J, Bergh A, Key T, Midttun O, Hallmans G, Ueland PM, Stattin P. One-carbon metabolism and prostate cancer risk: prospective investigation of seven circulating B vitamins and metabolites. Cancer Epidemiol Biomarkers Prev 2009;18: 1538-43.

41. Van Guelpen B, Hultdin J, Johansson I, Hallmans G, Stenling R, Riboli E, Winkvist A, Palmqvist R. Low folate levels may protect against colorectal cancer. Gut 2006;55: 1461-6. 
42. Mao B, Li Y, Zhang Z, Chen C, Chen Y, Ding C, Lei L, Li J, Jiang M, Wang D, Wang G. One-Carbon Metabolic Factors and Risk of Renal Cell Cancer: A Meta-Analysis. PLoS One 2015;10: e0141762.

43. Powers HJ. Riboflavin (vitamin B-2) and health. Am J Clin Nutr 2003;77: 1352-60.

44. Pangrekar J, Krishnaswamy K, Jagadeesan V. Effects of riboflavin deficiency and riboflavin administration on carcinogen-DNA binding. Food Chem Toxicol 1993;31: 745-50. 45. Colditz GA. Overview of the epidemiology methods and applications: strengths and limitations of observational study designs. Crit Rev Food Sci Nutr 2010;50 Suppl 1: 10-2. 


\section{University Library}

\section{- M I N E R VA}

\section{A gateway to Melbourne's research publications}

Minerva Access is the Institutional Repository of The University of Melbourne

\section{Author/s:}

Bassett, JK;Brinkman, MT;Dugue, P-A;Ueland, PM;Midttun, O;Ulvik, A;Bolton, D;Southey, MC;English, DR;Milne, RL;Hodge, AM;Giles, GG

Title:

Circulating concentrations of B group vitamins and urothelial cell carcinoma

Date:

2019-04-15

\section{Citation:}

Bassett, J. K., Brinkman, M. T., Dugue, P. -A., Ueland, P. M., Midttun, O., Ulvik, A., Bolton, D., Southey, M. C., English, D. R., Milne, R. L., Hodge, A. M. \& Giles, G. G. (2019). Circulating concentrations of $B$ group vitamins and urothelial cell carcinoma. INTERNATIONAL JOURNAL OF CANCER, 144 (8), pp.1909-1917. https://doi.org/10.1002/ijc.31927.

Persistent Link:

http://hdl.handle.net/11343/283673 